\title{
Haemodialysis vascular access function in dialysis patients at the Kenyatta National Hospital
}

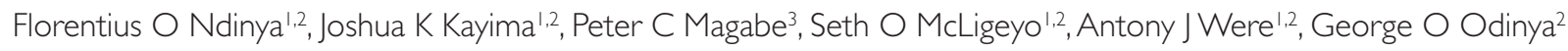 \\ 'Department of Clinical Medicine and Therapeutics, University of Nairobi, Kenya; ${ }^{2}$ Kenya Renal Association; ${ }^{3}$ Department of Diagnostic \\ Imaging and Radiation Medicine, University of Nairobi, Kenya.
}

\section{ABSTRACT}

Background: The number of patients requiring renal replacement therapy (RRT) worldwide has been on the rise. Vascular access is the lifeline for these patients when haemodialysis (HD) is the treatment of choice. Access-related morbidity is a leading cause of hospitalization so that the function and patency of access are essential for the optimal management of patients. There is a need to recognize when a vascular access is dysfunctional because intervention must maintain function as well as preserve future vascular access sites.

Methods: This was a cross-sectional study that evaluated the haemodialysis vascular access function in patients undergoing chronic haemodialysis at the Kenyatta National Hospital, Nairobi, Kenya. Peak access blood flow rates, urea reduction ratio (URR) and Kt/N were analysed in 150 patients.

Results: The temporary (non-tunnelled) central venous dialysis catheters had poor function, with only $48 \%$ achieving a mean blood flow rate $>300 \mathrm{~mL} / \mathrm{min}$. The comparable rate for arteriovenous fistulae (AVF) was $88 \%$ and for tunnelled dialysis catheters $82 \%$. One-quarter of the patients had a URR $<65 \%$. Higher mean blood flow rates were associated with higher URR $(P=0.004)$ and $K t / V(P=0.009)$ values. AVF stenosis was present in $12.5 \%$ and thrombosis in 3\% of patients. Aneurysms were the commonest AVF complication (47\%) but were not haemodynamically significant.

Conclusions: Tunnelled haemodialysis catheters offered adequate blood flows and achieved adequate delivered dialysis, comparable to arteriovenous fistulae. Non-tunnelled catheters delivered poor blood flow rates and dialysis dose. Greater blood flow rates were associated with a higher delivered dialysis dose. There is a need for routine surveillance and affordable interventional procedures to prevent loss of vascular access.

Keywords: haemodialysis; vascular access; Kenya; adequacy of dialysis.

\section{INTRODUCTION}

The worldwide prevalence of chronic kidney disease is estimated to be between $8 \%$ and 16\%. It is expected to rise disproportionately in developing nations, driven by diabetes and hypertension [I]. Renal replacement therapy (RRT) in the form of dialysis or renal transplantation is life-saving for patients who progress to endstage renal disease (ESRD). The number of patients with ESRD requiring renal replacement therapy has continued to increase worldwide $[\mathrm{I}-4]$.

In the year 2010, between 4.9 and 9.7 million people were estimated to require RRT; only 2.6 million received treatment. This treatment gap is fuelled by the growing populations from low-income nations in Africa and Asia. The number of people on RRT is projected to more than double to 5.4 million people by the year 2030 [5].

Around the world, $70 \%$ to $80 \%$ of patients who need RRT are initiated on haemodialysis (HD). In some parts of the world, such as Hong Kong and Mexico, peritoneal dialysis predominates as the preferred modality of RRT [6]. Vascular access is the lifeline for patients on HD and its function and patency are essential for efficient treatment. Low blood flow rates through the access and 
loss of patency limit HD delivery, may result in extension of treatment times and result in under-dialysis, leading to increased morbidity and mortality [7].

Measures to prevent access dysfunction include catheterlocking solutions (with heparin or citrate) and monthly blood flow rate surveillance for both central venous catheters (CVC) and arteriovenous fistulae (AVF). Measures to restore blood flow once dysfunction ensues include saline flushes, use of fibrinolytics, mechanical disruption of fibrin sheaths for CVCs and fistuloplasty or stenting for patients with an AVF $[8,9]$.

Access function can also be assessed by measuring the delivered dialysis dose. One method is calculation of $\mathrm{Kt} / \mathrm{V}$, where $\mathrm{K}=$ urea clearance, $\mathrm{t}=$ dialysis time and $\mathrm{V}=$ total body water. This index reflects the efficiency of dialysis and has been shown to correlate with morbidity and mortality of patients on HD [10-12]. Dialysis dose can also be assessed by calculating the urea reduction ratio (URR) [I3] after measuring blood urea concentrations before and after dialysis. Achieving a Kt/V $\geq 1.2$ or $U R R \geq 65 \%$ improves the outcomes of patients on HD [ 4$]$ and hence achieving this goal remains one of the aims of HD.

Achieving the targeted dialysis dose may require using high-flux dialysers or larger dialysers, increasing the blood flow or dialysate flow rates, or increasing the dialysis treatment time. Increasing treatment times and using high-flux dialysers cannot be used routinely owing to economic constraints as well as patients' reluctance to spend many hours on HD.

Measuring the flow across the vascular access is an important part of ensuring the delivery of effective dialysis [15] and we therefore evaluated the vascular access function in patients undergoing chronic haemodialysis at our hospital.

\section{METHODS}

A cross-sectional, descriptive study was conducted between January 2016 and March 2016 at the renal unit of Kenyatta National Hospital $(\mathrm{KNH})$, in Nairobi, Kenya, on patients 13 years or older who had been treated for ESRD with haemodialysis for at least one week. Dialysis was performed using a Nipro Surdial 55Plus machine or a Gambro AK96. Blood flow rates above $300 \mathrm{~mL} / \mathrm{min}$ are prescribed.

The assessment of peak blood flow was performed during the first hour of the treatment. A sustained maximum blood flow rate for at least 5 minutes was considered the peak access blood flow rate. Mean blood flow rate was the recorded average for the full HD session.
Each patient had $2 \mathrm{~mL}$ of blood collected pre- and postdialysis for urea testing. Samples were analysed using the BiOLiS 50i Superior machine. Kt/V was calculated using the Daugirdas formula: $K t / V=-\ln (R-0.03)+[(4-3.5 R) \times$ (UF/W)], where UF is the ultrafiltration volume in litres, $W$ is the post-dialysis weight in $\mathrm{kg}$, and $\mathrm{R}$ is the ratio of post-dialysis to pre-dialysis urea [16]. URR (\%) was calculated from the ratio (pre-urea - post-urea)/pre-urea $\times 100$.

Patients with an AVF underwent Doppler ultrasonography (using a Sonosite Fujifilm M-Turbo machine and a highfrequency $9-\mathrm{MHz}$ linear array transducer) of their access within two hours of dialysis. The following criteria were used for the diagnosis of AVF abnormalities:

I) Fistula stenosis: a circumscribed constriction of the vessel lumen within the AVF or in the region of the colour Doppler flow stream with turbulent high-velocity systolic flow and low diastolic flow by spectral Doppler.

2) Fistula thrombosis: an echogenic mass (thrombus) protruding into the vessel lumen, associated with partial or complete occlusion of the lumen.

3) Fistula aneurysm: a circumscribed dilatation of the AVF lumen with distinct borders filled with colour Doppler flow signals of low velocity.

The access blood flow for each patient was compared to the corresponding URR and Kt/ $\mathrm{V}$ after the dialysis session, to examine the access performance in relation to the dialysis dose achieved.

Ethical approval for the study was granted by the University of Nairobi Department of Clinical Medicine and Therapeutics and the $\mathrm{KNH}-\mathrm{U} O \mathrm{~N}$ Ethics Review Committee (reference number P532/08/20I5).

\section{RESULTS}

From January 2016 to March 2016, 156 consecutive patients on haemodialysis were screened for eligibility for the study and 150 were included. Approximately half of the patients were male (50.7\%) and most were young, with a mean age of $43 \pm 16.5$ years. The most common documented causes of kidney disease were hypertension (40\%) and glomerular disease (30\%). The duration of haemodialysis ranged from 2 weeks to 19 years with a median duration of 10.5 months. Approximately threequarters of the patients had been on dialysis for less than two years.

Table I summarizes the vascular access characteristics of the study population. The most common form of vascular access was a tunnelled central venous catheter (47\%), followed by non-tunnelled catheters (31\%) and AVF (23\%). 


\begin{tabular}{|lc|}
\hline \multicolumn{2}{|l|}{$\begin{array}{l}\text { Table I. Vascular access characteristics of the study } \\
\text { population }(\mathrm{n}=\mathrm{I50}) .\end{array}$} \\
\hline Current vascular access & $\mathrm{N}(\%)$ \\
Arteriovenous fistula & $34(23)$ \\
Cuffed, tunnelled catheter & $70(47)$ \\
Non-cuffed, non-tunnelled catheter & $46(31)$ \\
Duration of current access in months & Mean (range) \\
Arteriovenous fistula & $50.5(3.0-222)$ \\
Cuffed, tunnelled catheter & $8.3(0.3-43)$ \\
Non-cuffed, non-tunnelled catheter & $4.6(0.5-60)$ \\
First access & $\mathrm{N}(\%)$ \\
Arteriovenous fistula & $5(3)$ \\
Cuffed, tunnelled catheter & $24(16)$ \\
Non-cuffed, non-tunnelled catheter & $121(81)$ \\
Reason for change from first access $(\mathrm{n}=85)$ & $\mathrm{N}(\%)$ \\
Poor flow & $46(31)$ \\
Need for permanent access & $1 \mathrm{I}(7)$ \\
\hline
\end{tabular}

Almost all the patients had been initiated on haemodialysis using a central venous haemodialysis catheter. The commonest site of insertion was the subclavian vein (87\%), followed by the internal jugular vein (12\%) and femoral vein (1\%). Arteriovenous fistulae were most commonly brachiocephalic (53\%) or radiocephalic (44\%), and in one patient, brachiobasilic (3\%). In general, arteriovenous fistulae were in use for a longer duration with the longest in use for 18 years.

A large proportion of patients (85\%) were dialysed twice a week. All dialysis sessions were scheduled for 4 hours and the mean blood volume processed was $76 \mathrm{~L}$. The peak blood flow rates for the group ranged from 180 to $480 \mathrm{~mL} /$ min and the mean blood flow rate, URR and $\mathrm{Kt} / \mathrm{V}$ were $311.5 \mathrm{~mL} / \mathrm{min}, 69.8 \%$ and 1.5 , respectively. The dialysis session variables are summarized in Table 2.

Table 3 summarizes blood flow rates, URR and Kt/V by vascular access type. Adequate blood flow rates ( $\geq 300 \mathrm{~mL} / \mathrm{min}$ ) were achieved by $88 \%, 82 \%$ and $48 \%$ of patients using AVF, tunnelled and non-tunnelled catheters, respectively. Patients with AVF achieved higher blood flow rates and better urea clearances. On Doppler ultrasonography, $72 \%$ of these AVF patients had blood flows $>$ $500 \mathrm{~mL} / \mathrm{min}$. Lower blood flow rates were associated with
Table 2. Dialysis session characteristics $(n=150)$.

\begin{tabular}{|c|c|}
\hline & Mean (range) \\
\hline \multicolumn{2}{|l|}{ Frequency of dialysis sessions (\%) } \\
\hline I) Once a week & 12.0 \\
\hline 2) Twice a week & 85.2 \\
\hline 3) Irregular & 2.7 \\
\hline Urea concentration before dialysis (mmol/L) & $27.1(7.8-58)$ \\
\hline Urea concentration after dialysis (mmol/L) & $8.1(2.1-3 \mid)$ \\
\hline Urea reduction ratio (\%) & $69.8(29.6-87.8)$ \\
\hline $\mathrm{Kt} / \mathrm{V}$ & $1.5(0.4-2.5)$ \\
\hline Peak blood flow rate $(\mathrm{mL} / \mathrm{min})$ & $368.3(180-480)$ \\
\hline Mean blood flow (mL/min) & $311.5(175-373.3)$ \\
\hline Total volume of blood processed (L) & $76.0(42.0-89.6)$ \\
\hline Ultrafiltration volume (L) & $2.3(0.4-5.0)$ \\
\hline
\end{tabular}

Table 3. Blood flow rates, URR and $\mathrm{Kt} / \mathrm{V}$ by vascular access type.

\begin{tabular}{|ccccc|}
\hline & $\begin{array}{c}\text { Arterio- } \\
\text { venous } \\
\text { fistula }\end{array}$ & $\begin{array}{c}\text { Tunnelled } \\
\text { catheter }\end{array}$ & $\begin{array}{c}\text { Non- } \\
\text { tunnelled } \\
\text { catheter }\end{array}$ & P value \\
MBF $(\mathrm{mL} / \mathrm{min})$ & 330.1 & 330.1 & 290.7 & $<0.001$ \\
$\mathrm{MPF}(\mathrm{mL} / \mathrm{min})$ & 399.2 & 399.2 & 336.3 & $<0.001$ \\
Mean Kt/V & 1.6 & 1.6 & 1.4 & $<0.001$ \\
Mean URR (\%) & 70.9 & 70.9 & 67.2 & $<0.001$ \\
\hline
\end{tabular}

Abbreviation: URR, urea reduction ratio; MBF, mean blood flow rate; MPF, mean peak flow rate.

poor dialysis dose as assessed by URR (Figure I). On the contrary, only $15.1 \%$ of patients with a mean blood flow rate above $300 \mathrm{~mL} / \mathrm{min}$ had a URR less than $65 \%$.

Venous aneurysms were the most common complications seen in patients with an AVF (47\%). Other complications observed included 6 patients with anastomotic stenosis. Two of these patients had mild stenosis that did not affect the blood flow through the access. The prevalence of haemodynamically significant stenosis was $12.5 \%$. All affected patients had stenosis on the venous side of the anastomosis. Two had additional severe upstream stenosis with subsequent thrombosis of the access on follow-up after one week. High flow rates were seen in 6 patients, of whom one presented with a steal syndrome and two with venous hypertension. 


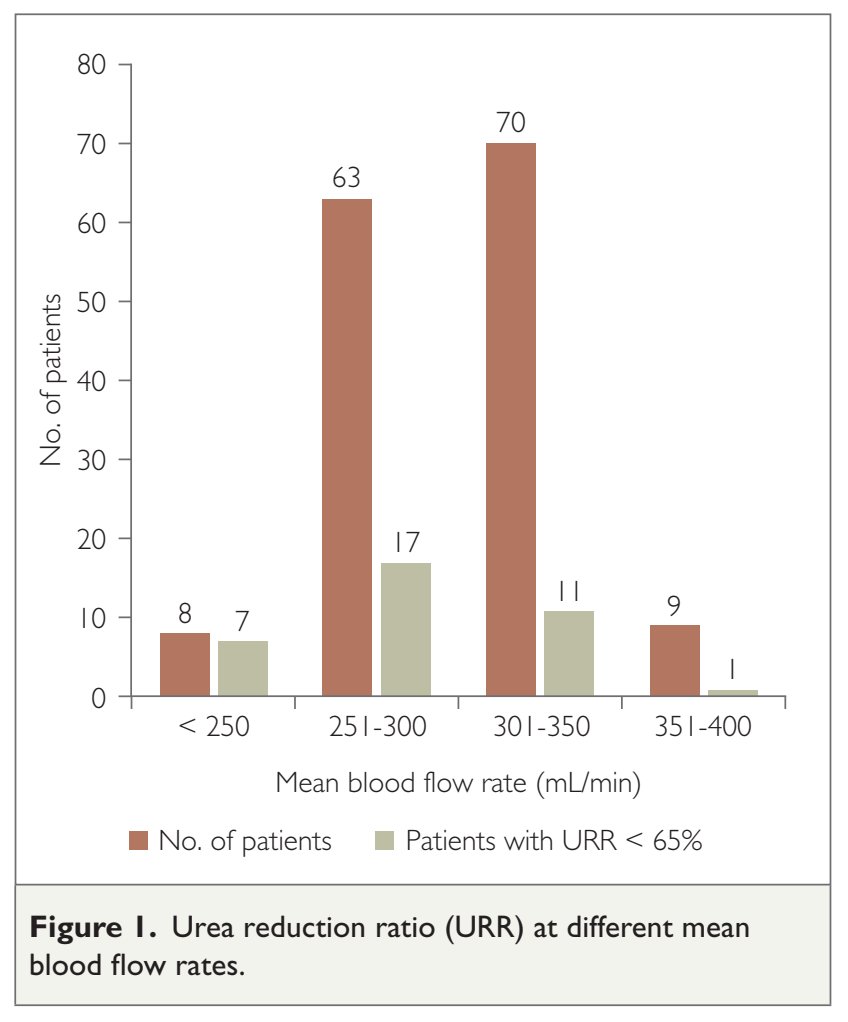

Bivariable analysis revealed an association between mean blood flow rate and $\mathrm{Kt} / \mathrm{V}(P=0.006)$ as well as URR $(P=0.004)$. URR was also associated with age $(P=0.009)$ and weight $(P<0.00 \mathrm{I})$. There was no association between URR and the type of vascular access $(P=0.078)$ but there was an association between $\mathrm{Kt} / \mathrm{V}$ and the type of access $(P=0.015)$, age $(P=0.00 I)$ and weight both before and after dialysis $(P<0.00 \mathrm{I})$.

\section{DISCUSSION}

Our study population was young and similar to previous studies from the Kenyatta National Hospital [17,18]. Glomerular disease was the presumed cause of renal disease in one-third of the patients. Hypertension was common but its presence could be a consequence of the renal disease and not necessarily the cause. Most participants had been on dialysis for less than 2 years, which may reflect a high dropout rate due to the socio-economic burden of financing treatment, a high mortality rate, or early renal transplantation.

There has been a shift in vascular access creation and usage at the $\mathrm{KNH}$ since the late 1980s when arteriovenous shunts and arteriovenous fistulae were the predominant forms of vascular access for haemodialysis [19]. Central venous catheter usage has been on the increase [17] and threequarters of the patients in the present study were using CVCs. The tunnelled catheter has become an acceptable particularly in settings where arteriovenous fistulae or arteriovenous grafts cannot be created [6]. Catheter usage in our study was in excess of the NKF-DOQI recommendations that they be used in less than 10\% of patients [8]. This may be explained by the late presentation of patients, the lack of a dedicated vascular surgery team and the absence of routine vascular access surveillance.

Most of our vascular accesses achieved the minimum recommended mean blood flow rate $(300 \mathrm{~mL} / \mathrm{min})$ [8]. Higher mean blood flow rates were associated with a high delivered dialysis dose. Higher Kt/V and URR values were associated with younger age and lower body mass. One-quarter of our patients had mean blood flow rates $<300 \mathrm{~mL} / \mathrm{min}$ and this was mostly due to the use of non-tunnelled catheters. Poor delivered dialysis dose, as determined by URR and Kt/ $\mathrm{V}$, was observed in one-fifth to one-quarter of patients. Almost all patients with mean blood flow rates $<250 \mathrm{~mL} / \mathrm{min}$ recorded poor delivered dialysis dose.

In a multi-centre study in Iran of 4004 patients, the mean blood flow rate achieved was $243 \mathrm{~mL} / \mathrm{min}$, and the percentage of patients with $\mathrm{Kt} / \mathrm{V}<1.2$ and URR $<65 \%$ were $56.7 \%$ and $65.2 \%$, respectively [20]. This emphasizes the contribution of low blood flows to inadequate dialysis but also serves as a reminder that other variables such as age, pre-dialysis weight, time on dialysis and access recirculation play a role in the dialysis dose delivered [15,2I]. The study reported a tendency to better performance with an AVF access (mean blood flow $330 \mathrm{~mL} / \mathrm{min}$ and $\mathrm{Kt} / \mathrm{V} \mathrm{I.6)}$ ) as compared to tunnelled catheters (mean blood flow rate $316 \mathrm{~mL} / \mathrm{min}$ and $\mathrm{Kt} / \mathrm{V}$ 1.5). Similar findings were demonstrated by Canaud et al., where mean blood flow rates for AVF and tunnelled catheters were $340 \mathrm{~mL} / \mathrm{min}$ and $316 \mathrm{~mL} / \mathrm{min}$, respectively, with higher $\mathrm{Kt} / \mathrm{V}$ measurements for patients with an AVF [22]. In a Canadian study of 259 patients with a tunnelled HD catheter [15], the mean blood flow rate achieved was $352 \mathrm{~mL} / \mathrm{min}$ and the proportion of patients with URR $<65 \%$ was $10.5 \%$. The better performance measures could be due to their practice of routine vascular access blood flow and dialysis dose measurements.

Most of our patients underwent twice-weekly dialysis; the remainder dialysed less frequently, mainly for economic reasons. Dialysis sessions lasted a standard time of 4 hours for all patients. The recommendations for $\mathrm{Kt} / \mathrm{V}$ of 1.2 or URR of at least 65\% [23] are based on patients dialysing three times a week. The recommended dosing for twiceweekly HD is $\mathrm{Kt} / \mathrm{V} \geq 2$ [24]. This can be achieved by lengthening treatment times [25] and increasing blood flow rates. 
AVF assessment by Doppler ultrasound revealed adequate flows in around half of our patients (53\%). The percentage of stenosis (19\%) was low compared with other studies at $45.5 \%$ and $64 \%[26,27]$. Thrombotic events in other studies ranged between 17\% and 25\% [28]. Two of our patients lost their AVF due to thrombosis; intervention to restore function could not be undertaken for financial reasons. The stenotic lesions were located on the venous side of the anastomosis in six patients; two patients had additional long stenotic lesions in the efferent vein. Aneurysms were common but did not interfere with the functioning of the AVF. Intervention would be considered for cosmetic purposes or when there is overlying skin thinning with risk of rupture [29].

\section{CONCLUSIONS}

This study demonstrates that most haemodialysis vascular accesses in use at the $\mathrm{KNH}$ renal unit have adequate flow rates. Arteriovenous fistulae provided better blood flow rates and dialysis dose, but there is a need to implement routine surveillance and make interventional procedures affordable to prevent loss of access. Tunnelled catheters provided adequate blood flows and dialysis dosages that were comparable to arteriovenous fistulae. Non-tunnelled catheters delivered poor blood flow rates and dialysis dose and are in use for longer than the recommended duration.

\section{REFERENCES}

I. Jha V, Garcia-Garcia G, Iseki K, et al. Chronic kidney disease: Global dimension and perspectives. Lancet. 20।3; 382(9888):260-272.

2. Eggers PW. Has the incidence of end-stage renal disease in the USA and other countries stabilized? Curr Opin Nephrol Hypertens. 20II; 20(3):24I-245.

3. Arogundade FA, Barsoum RS. CKD prevention in Sub-Saharan Africa: a call for governmental, nongovernmental, and community support. Am J Kidney Dis. 2008; 5 I (3):5 I5-523.

4. South African Renal Registry Annual Report 2012. Available from: http://www.sa-renalsociety.org/Registry.asp.

5. Liyanage $T$, Ninomiya $T$, Jha $V$, et al. Worldwide access to treatment for end-stage kidney disease: a systematic review. Lancet. 2015 385(998।): 1975-1982.

6. USRDS 2012 Annual Data Report. Bethesda, MD: National Institutes of Health, National Institute of Diabetes and Digestive and Kidney Diseases.

7. Hakim RM, Breyer J, Ismail N, et al. Effects of dose of dialysis on morbidity and mortality. Am J Kidney Dis. 1994; 23:66I-669.

8. Clinical practice guidelines for vascular access. Am J Kidney Dis 2006; 48(Suppl I):S248-S273.

9. Clinical practice guidelines for vascular access. Am J Kidney Dis. 2006; 48(Suppl I):SI76-S247.

10. Held PJ, Port FK, Wolfe RA, et al. The dose of hemodialysis and patient mortality. Kidney Int. 1996; 50(2):550-556.
I I. Lowrie EG, Laird NM, Parker TF, et al. Effect of the hemodialysis prescription of patient morbidity: report from the National Cooperative Dialysis Study. N Engl J Med. 198|; 305: | |76-I I 8I.

12. Gotch FA, Sargent JA. A mechanistic analysis of the National Cooperative Dialysis Study (NCDS). Kidney Int. 1985; 28(3):526-534.

13. Owen WF, Lew NL, Liu Y, et al. The urea reduction ratio and serum albumin concentration as predictors of mortality in patients undergoing hemodialysis. N Engl J Med. 1993; 329:1001-1006.

14. Lindsay RM, Spanner E. Adequacy of haemodialysis in the elderly. Geriatr Nephrol Urol. 1997; 7(3): |47-156.

15. Moist LM. Relationship between blood flow in central venous catheters and hemodialysis adequacy. Clin J Am Soc Nephrol. 2006; I (5):965-97।.

16. Daugirdas JT. Second generation logarithmic estimates of single-pool variable volume Kt/V: An analysis of error. J Am Soc Nephrol. 1993; I8(4): | 205-1213.

17. Shosi RA, Mcligeyo SO, Kayima J, Twahir M, et al. The adequacy of haemodialysis in end stage renal disease at Kenyatta National Hospital [MMed thesis]. University of Nairobi, 2003.

18. Soki KB, Were AJ, Ogola EN, Nyale GM, Murage MM. An echocardiographic evaluation of pulmonary pressures in hemodialysis patients at Kenyatta National Hospital, Nairobi, Kenya. East Afr Med J. 2017; 94(6):472-481.

19. Ngugi PN, McLigeyo SO, Kayima JK, et al. Vascular access for haemodialysis. East Afr Med J. 1991; 68(6):442-447.

20. Amini M, Aghighi M, Masoudkabir F, et al. Hemodialysis adequacy and treatment in Iranian patients: a national multicenter study. Iran J Kidney Dis. 201 I; 5(2): 103-109.

21. Depner TA. Hemodialysis adequacy: basic essentials and practical points for the nephrologist in training. Hemodial Int. 2005; 9(3):241-254

22. Canaud B. Effective flow performances and dialysis doses delivered with permanent catheters: a 24-month comparative study of permanent catheters versus arterio-venous vascular accesses. Nephrol Dial Transplant. 2002; 17(7): I286-1292

23. Hemodialysis Adequacy 2006 Work Group. Clinical practice guidelines for hemodialysis adequacy, update 2006. Am J Kidney Dis. 2006; 48(Suppl I):S2-90

24. Panaput T, Thinkhamrop B, Domrongkitchaiporn S, et al. Dialysis dose and risk factors for death among ESRD patients treated with twice-weekly hemodialysis: a prospective cohort study. Blood Purif. 2014; 38(3-4):253-262.

25. Bieber B, Qian J, Anand S, et al. Two-times weekly hemodialysis in China: frequency, associated patient and treatment characteristics and Quality of Life in the China Dialysis Outcomes and Practice Patterns study. Nephrol Dial Transplant. 2014; 29(9): I770-1777.

26. Moghazy KM. Value of color Doppler sonography in the assessment of hemodialysis access dysfunction. Saudi J Kidney Dis Transpl. 2009; 20( I):35-43

27. Pietura R, Janczarek M, Zaluska W, et al. Colour Doppler ultrasound assessment of well-functioning mature arteriovenous fistulas for haemodialysis access. Eur J Radiol. 2005; 55( I): I I3-1 I9

28. Stolic R. Most important chronic complications of arteriovenous fistulas for hemodialysis. Med Princ Pract. 20 I 3. p. 220-228.

29. Kumbar L. Complications of arteriovenous fistulae: beyond venous stenosis. Adv Chr Kidney Dis. 2012; 19(3): 195-201. 